\title{
Sustainability assessment of electricity production using a logic models approach
}

\author{
Fernando Ribeiro, Paula Ferreira*, Madalena Araújo \\ University of Minho, Center for Industrial and Technology Management, Campus Azurem, 4800-058 Guimaraes, Portugal
}

\section{A R T I C L E I N F O}

Article history:

Received 5 June 2012

Received in revised form

28 May 2013

Accepted 20 July 2013

Available online 24 August 2013

Keywords:

Electricity production

Impact assessment

Logic models

Experts' interviews

\begin{abstract}
A B S T R A C T
The topic Sustainable Development has brought a wide discussion across a number of sectors in our society, namely in Power Systems. Given the need to address other concerns than the economic ones, decision makers must take into account the rationale that lies beneath strategic choices, such as investing in generation technologies using renewable energy or rather doing business as usual and installing fossil fuel power plants. In this paper logic models were used as a decision-aid supporting tool, with the aim of contributing to the assessment of the possible impacts of different power plants in terms of sustainable development. The analyzed electricity generation technologies were grouped in thermal, renewable energy sources (RESs) and nuclear. The literature review fed the construction of three relational diagrams to allow the visualization of environmental, social and economic causes and effects of the three groups of technologies. Departing from these initial diagrams a set of interviews with experts was conducted to enrich and validate the logic models. The results of the literature review and of these interviews allowed to conclude that the use of RES has wider positive social impacts on the long run, despite their short-term higher costs compared to the traditional groups (nuclear and thermal). These logic models revealed to be a useful tool providing a valuable starting approach for an Impact Assessment of the ongoing change that power systems have been going through.
\end{abstract}

(c) 2013 Elsevier Ltd. All rights reserved.

\section{Contents}

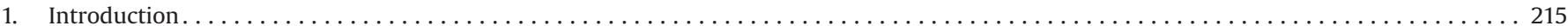

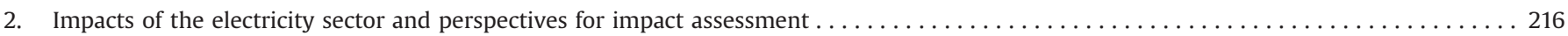

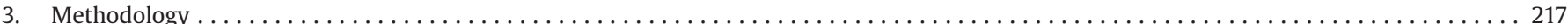

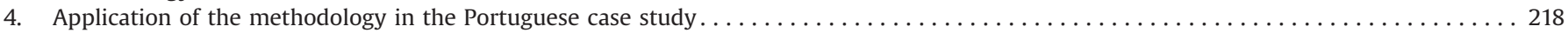

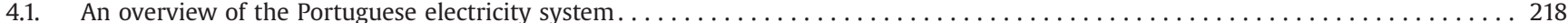

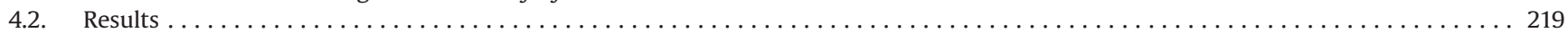

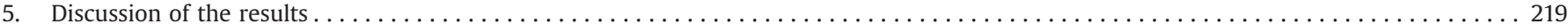

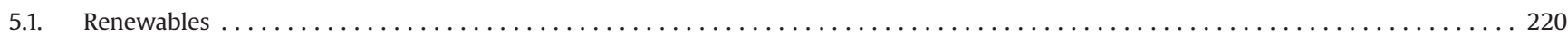

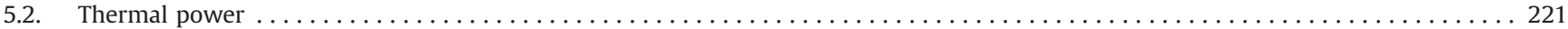

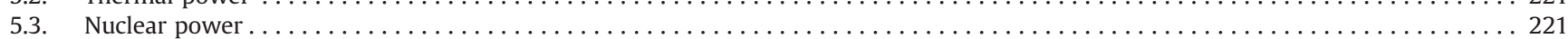

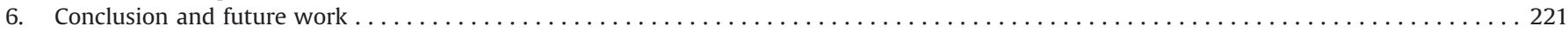

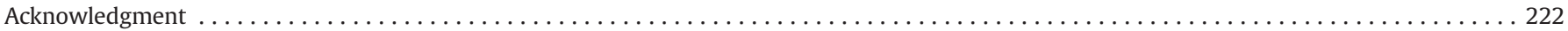

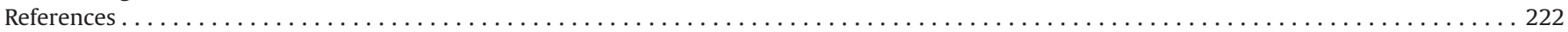

\section{Introduction}

Among the strategies envisioned by the European Union, two of them concern especially power systems: the 20-20-20

\footnotetext{
* Corresponding author. Tel.: +351253511670.

E-mail addresses: fernandor@dps.uminho.pt (F. Ribeiro), paulaf@dps.uminho.pt (P. Ferreira),mmaraujo@dps.uminho.pt (M. Araújo).
}

and the European Union Sustainable Development Strategy (EUSDS).

1. The EUSDS aims the building of a European Union respecting the inter-generational principle, while achieving full employment through a competitive social market economy and balanced economic growth, among other objectives [1].

2. The 20-20-20, with a horizon of 2020 , points to a reduction of $20 \%$ of primary energy consumption with the improvement of 
energy efficiency, a minimum share of renewable energy of $20 \%$ and the reduction of greenhouse gases to $20 \%$ below the 1990 values [2].

The authors addressed in past works social issues in power systems planning [3,4]. From the literature related to electricity generation they concluded that the methodologies explicitly expressing economic, social and environmental criteria fall mostly on Multi-Criteria Decision Aid (MCDA). It is clear in the literature that ultimately the economic and environmental criteria still prevail, given the "soft" aspects of the social issues. Additionally, given the inter-relation between different groups of criteria (and the expression "socio-economic" proves it) situations exist where some short term non-optimal cost choices can be supported under the perspective of inducing virtuous cycles of social welfare and long-run economic return, as it is advocated, generally, by many who support investment on renewables, as advocated in National Renewable Energy Plans, for example in the Portuguese case [5].

In these terms, it becomes necessary to organize the rationale behind the support of the strategic importance that different groups of electricity generation technologies assume. This paper aims at contributing to this issue, by exploring the construction of diagrams allowing for the visualization of impact chains associated with different technologies. These logic models should provide a good starting point for an Impact Assessment of the ongoing change that power systems have been going through.

For drawing these models, the paper follows a methodology combining both literature review and participative methods. The application of the methodology is shown for the particular case of the Portuguese electricity system. The results of this work are three logic models, one for each group of electricity generation technology: thermal, nuclear and renewables. The information was gathered using a combination of data gathering using primary sources of literature (consultant reports and government strategy documents) and interviews with experts invited to collaborate with the study team.

The remainder of the paper is as follows: Section 2 overviews the impacts of electricity generation and addresses the need of using logic models framed on an Impact Assessment perspective; Section 3 describes the used methodology; Section 4 presents the structure of the power generation in Portugal, along with the results; Section 5 focuses on discussion. Finally, Section 6 summarizes conclusions and points directions for future work.

\section{Impacts of the electricity sector and perspectives for impact assessment}

The ongoing changes in the electricity sectors have been influenced by policies aiming to mitigate climate change, "one of the defining challenges of our times", according to the United Nations Development Program [6]. The UNDP calls for the need of integration of climate policies in planning, so that projects that support development - a field where energy has proven to be essential - can better withstand the effects of climate change [6].

The production and use of electricity have environmental and social consequences at local, regional, and global levels. The European Commission maintains that impacts should be assessed over their lifetimes [7]. Although this introduces a good deal of uncertainty for long term impacts, such as those of global warming or high level radioactive waste disposal, to ignore them might suggest that they are unlikely to be of any importance in concrete impact assessment studies. Impact assessment of the energy sector has been widely addressed in the literature; for an overview see for example Jegarl [8], addressing the mitigation of $\mathrm{CO}_{2}$ in the energy sector, Tolis [9] for electricity expansion planning under emissions allowances and Hugé [10] for general sustainability issues on energy policy. Most of the literature on sustainability implications of power generation appears to belong to renewable energy studies, and they tend to focus on local impacts: for example Del Río \& Burguillo [11] review the literature of these aspects, and refer to social cohesion, municipal budget, industry creation and employment. They also address the importance of consuming endogenous resources and research \& development induced by the introduction of new technologies.

Sastresa et al. [12] apply a methodology to measure impacts of establishing renewable energy on a regional scale. The impacts measured are job creation and its quality, as well as development of the territory in technological development, per capita income, territorial development and human capital. Another study aiming to rank the different forms of power generation under a number of sustainability criteria, also concluded that these impacts, considered "external benefits", were higher for the renewable forms of power generation. On the other hand, the ranking is the reverse for the economic factors: nuclear represents lowest costs, followed by coal and natural gas [13]. The same study places nuclear power with the lowest $\mathrm{CO}_{2}$ emissions. Under the $\mathrm{CO}_{2}$ emissions perspective, nuclear power still shows potential for a contribution, given it is $\mathrm{CO}_{2}$-free [14]. But the long term impacts of radioactive waste potentially, along with large consequences of an accident such as the recent Fukushima's in Japan, is driving countries to commit to shut down nuclear power plants. On the other hand, the expansion of renewable energy technologies has resulted in increasing opposition in parts of the affected local population because of increasing negative amenity impacts. Potential impacts on local ecosystem from e.g. hydro plants, offshore wind parks or biomass plantations, in particular, have raised objections from green interest groups which traditionally consider renewable technologies as a viable alternative to nuclear power [15]. As for the RES technologies, the impacts of atmospheric emissions from these RES fuel cycles are insignificant in comparison to those from fossil fuels. The most important environmental effects of operating wind turbines are impacts on human amenity, namely noise and visual intrusion. As for the hydro fuel cycle, the main impacts are on land use, cultural objects and on aquatic and terrestrial ecosystems. The major impacts seem to be local and immediate, contrasting with fossil fuel cycles. Notwithstanding, the sustainable development goals imply that the evaluation of different technologies must include also the social dimension and, as derives from the Brundtland report [16], the wellbeing of future generations must be a priority. Employment appears to be a much cited social impact in electricity generation impact assessment. Several examples of this concern may be found in the literature addressing wind [17], photovoltaic technology [18], or even the whole energy system as is the case of Capros [19].

Impact assessment aims at structuring and supporting the development of policies [20]. According to Leeuw and Vaessen [21], "impact" is often associated with the level of welfare of households and individuals. Impact evaluation presupposes there is an institutional intervention ("impact of what?") that produces results ("impact on what?"). Leeuw and Vaessen [21] recognized that currently there is a shift in impact assessment, from small programs such as irrigation in a given district to more complex interventions, induced by international treaties such as the Kyoto Protocol. The impacts studied can focus environmental concerns (Environmental Impact Assessment), social aspects (Social Impact Assessment) or can address both in an integrated way (in the so-called Sustainability Impact Assessment) [22].

Bäcklund [23] overviews the importance of impact assessment in the European Union since 2000, and stress its increasing 
usefulness as a decision support tool. Within the EU, since 2002 the single-sector assessment was replaced by a new integrated approach, capable of assessing economic, environmental and social effects [24]. This new approach allows logic models or impact chains to be used when providing stakeholders with a visual map or narrative description of how specific program components are related to the program's desired results [25].

The literature related to logic models shows they have been applied in a vast array of purposes, such as the monitoring of national R\&D programs (for example Kim et al. [26] and Oros et al., [27]), education programs (for example [28] and Medeiros and Buktus [29]), cancer prevention programs [30], domestic violence prevention programs [31], technology-education programs [32], immunization programs [33] or evaluation of intervention services for children with disabilities [34]. To the authors' best knowledge, the use of logic models was not attempted to address changes in the electricity production sector. The present work aims to help filling this gap, giving a contribution to support impact assessment reports in the line of ECORSYS [24].

Electricity production in the EU has become liberalized in the last decades. The role of the government as a central planning authority tends to be reduced and mostly previously state-owned companies and facilities tend to be privatized. Although under liberalization the government no longer oversees the entire planning process, the electricity sector decisions are still strongly driven by central authorities, addressing issues such as GHG emission limits, RES shares, external energy dependency or universal access to electricity. As a result, the market still tends to be guided. So, to the questions "impact of what?" and "impact in what?", we may answer impact of energy policy upon the standards of living of the population, having in the background the contribution of power systems to sustainable development.

Another important aspect of impact assessment appears to be the public involvement in the decision-making. O'Faircheallaigh [35] addresses this issue in the context of Environmental Impact Assessment and concluded that the public pressure can result in the redefinition of public participation in decision-making. Examples of application of public participation in impact assessment studies include nuclear power decommissioning projects [36] and offshore renewable energy facilities [37], among others. Participative processes are frequent in the sustainability evaluation of energy projects or technologies, resourcing to experts' interviews or surveys due to the complexity of the topic and to the need to assess the societal effects under the sustainability concept, as was the case of Gamboa and Munda [38], Kowalksi et al. [39], Carrera and Mack [40], Karger and Hennings [41] and, more recently, Kaya et al. [42] and Adams et al. [43].

The impact assessment evaluation must address both regional and global perspectives and short, medium and long term impacts must be properly accounted for. The possibility of combining all this information in a single diagram that allows visualizing the impact chains for a system as complex as the electricity generation is, beyond any doubt, the major strength of the use of logic models as proposed.

\section{Methodology}

The objective of this paper is to organize the perceived short, medium and long-term impacts of electricity generation technologies, with the ultimate goal of supporting the sustainability assessment of the Portuguese power system and providing valuable information for future strategic decisions in the electricity sector. For that purpose, logic models were built firstly with the aid of a literature review and secondly of interviews with a group of experts, as explained in the remainder of this section. As a whole, the methodology followed is described in Fig. 1.

MacLaughin et al. [44] dedicated an article to the use of Logic Models for program performance evaluation, and described a five stages process to achieve the Logic Model. The present work was conducted upon their guidelines, adapted to the topic under research:

(1) Collecting the relevant information: emphasizing the team work needed for building a Logic Model along with the evidence that multiple perceptions about power planning exist, experts in power systems with varied positions on key questions such as markets in general and the renewable energy sources' role, were contacted and invited to enter the process. Documents used to build preliminary inference diagrams were consulted, namely APREN \& Deloitte [45] and APREN [46].

(2) Clearly defining the problem and its context: here the assumption is that a problem, the power generation planning, is to be solved under resource constraints and framed on the European energy policies, as well as a globalized competitive market. Therefore, the power planning has to allow the electricity demand to be met using three groups of solutions (thermal, renewable and nuclear), while addressing economic, environmental and social issues.

(3) Defining the elements of the logic model: starting with three tables constructed based on the literature review (one for each Logic Model) with resources, activities, outputs and outcomes, the interviewees were encouraged to comment on implications brought by the building and operation of each type of power plants, and fill the table, while seeking to describe short, medium and long term outcomes. The outcomes have to be somehow related to sustainability pillars (economy, environment and social development).

(4) Drawing the logic models: combining the literature review and the interviews, the logic models were built for each group of technologies. Results are presented further in the next section.

(5) Verifying the logic models with stakeholders: a draft version of the logic models was presented to all participants in the end

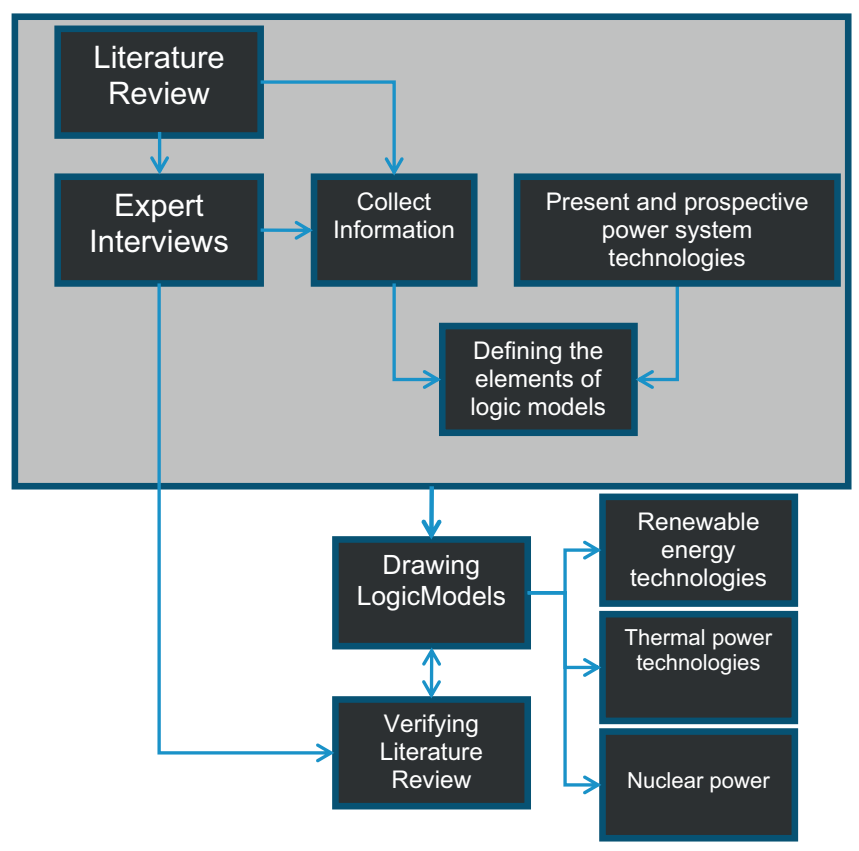

Fig. 1. The used methodology to achieve the logic models. 
of the interviews aiming to validate the results and ensure the validity of the proposed logic models for each technology or group of technologies under study.

Following the literature analysis semi-structured interviews were conducted with energy experts and local stakeholders with an active role on energy projects. Interviewees' included people from industry, environment and economy consultants, renewable energy associations along with academics (industrial, power systems engineering or energy economics researchers) and representatives of local communities. With the support of the internet, people involved in energy projects or energy decision making in Portugal were identified. Additional interviewees came from contacts made in course of the research. This procedure led to include 9 interviewees in this study.

The interviews lasted $45 \mathrm{~min}$, on average. The interviewees were firstly presented an example of a logic model to get acquainted with the goals of the interview. The theme of the example was an European strategy to help reduce poverty, in order to avoid biases about sustainable development and energy. Participants were then invited to talk about economic, environmental and social impacts associated to each group of technologies, starting from the long-term perspective (example: how do you think that environment will get better if these technologies are used?) and progressing from there to more immediate impacts (which immediate impacts does the construction of this type of power plants cause?).

While the interviewee was talking, the interviewer was filling the table with short, medium and long-term impacts and would then present it to the interviewee.

The interviewer prepared, before closing the interview and before getting the final results, a simple logic diagram and tables, aiming to discuss them further with the interviewee and possibly completing the diagram with more impacts and connections that have arisen in the process.

\section{Application of the methodology in the Portuguese case study}

\subsection{An overview of the Portuguese electricity system}

Electricity in Portugal is mainly generated from hydro, thermal and wind power. Thermal power is provided with coal and CCGT (combined cycle gas turbines) power plants. The Portuguese electricity system is strongly influenced by the rainfall characteristics. Although the large hydropower installed capacity remained almost unchanged between 2006 and 2010, in fact the hydro production presented strong variations during this period. In 2007, the Portuguese state launched a new plan for installing more hydropower, known as PNBEPH (Plano Nacional de Barragens de Elevado Potencial Hidroeléctrico) [47]. It aimed to reduce the unused hydropower potential from 54\% to 33\% until 2020, installing new $2059 \mathrm{MW}$. This was expected to be achieved by two means: increasing installed power of already existing facilities (909 MW), and building 10 new hydropower plants totaling $1150 \mathrm{MW}$ of installed power. Among these projects, some include pumping capacity, justified to deal with new wind power to be installed.

In 2007 the PNBEPH forecasted that in 2010 there would be $5100 \mathrm{MW}$ of installed wind power, which contrasted with the $3751 \mathrm{MW}$ achieved in reality [48]. As a result, the accomplishment of these plans is obviously constrained by political and other factors (such as the fall of electricity consumption in 2010 and 2011 shown in Ref. [49]). The future of the Portuguese power system remains then uncertain.
The total electricity produced in Portugal, in 2010, was roughly $50 \mathrm{TWh}$, generated by different technologies, as shown in Fig. 2. Since 2010 was an above average rain year, the results were corrected using the hydraulicity productivity index, measured as the ratio between the effective hydropower production and the corresponding value that would be expected under average conditions. Note also that nuclear power is not present in the Portuguese electricity system. However, it was decided to address it in the present study because it is an option frequently discussed in Portugal. The label Special Regime Production (SRP) is the denomination for the group of technologies that are presently subsidized with feed-in tariffs, as described in Fig. 3.

Special Regime Production has been increasing, mainly due to the growth of wind farms, departing from only $152 \mathrm{MWh}$ of wind power production in 2000 to 8.9 TWh produced in 2010 [50]. NonRenewable Cogeneration refers mainly to industrial use of natural gas and fuel oil for both heat and electricity generation, whereas renewable cogeneration uses biomass instead.

Both figures put in evidence the importance of RES for the Portuguese electricity system, strongly supported by incentives in particular feed-in tariffs. However, their effective contribution for a sustainable electricity system is frequently questioned mainly, but not only, under the cost argument. The complexity of the theme and the diversity of the expected impacts of different electricity generation technologies under a sustainable development perspective,

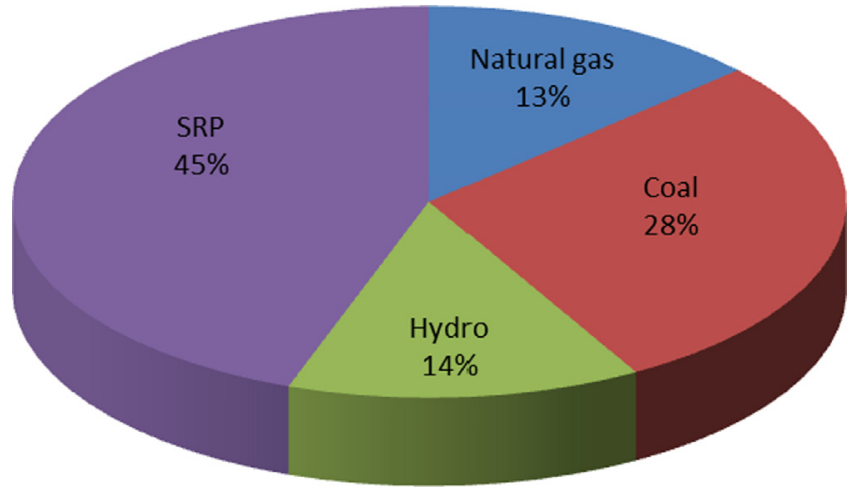

Fig. 2. Production of electricity in 2012

Source: Own elaboration from data available in Ref. [48].

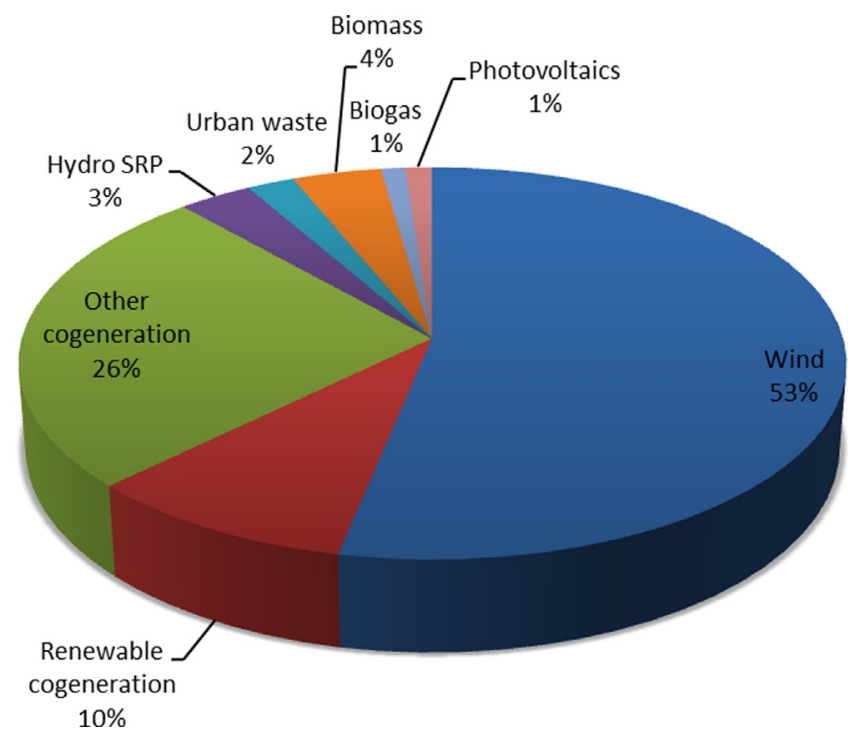

Fig. 3. Share of electricity produced from different SRP technologies in 2012. Source: Own elaboration from ERSE [49]. 
justify the search for a tool explicitly detailing these impacts, their importance and their timeframe.

\subsection{Results}

Based on the literature review and on the interviews, three logic models were drawn, presenting the impacts of electricity generation technologies or groups of technologies as shown in Figs. 4-6.

\section{Discussion of the results}

Decision-makers with different political points of view will tend to favor different political aspects of strategies about energy. The most visible example is the position towards market prices in short-term. As electricity costs affect a wide number of commodities, it can be argued that it is essential for a country to provide cheap electricity. Otherwise the country will lose competitiveness, and eventually impoverish by losing industry and other economic sectors. And it is widely agreed that, presently, the traditional

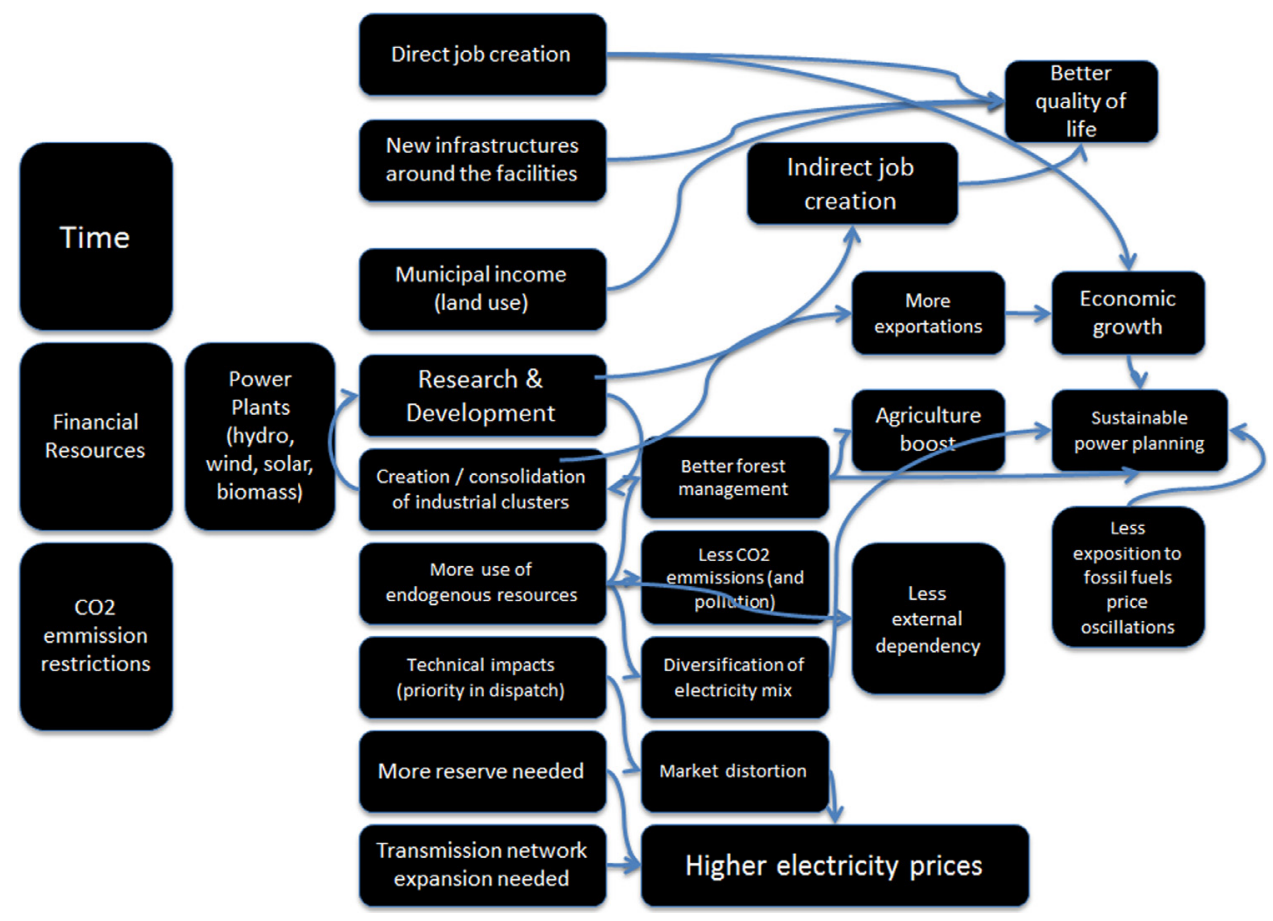

Fig. 4. The logic model for RES technologies.

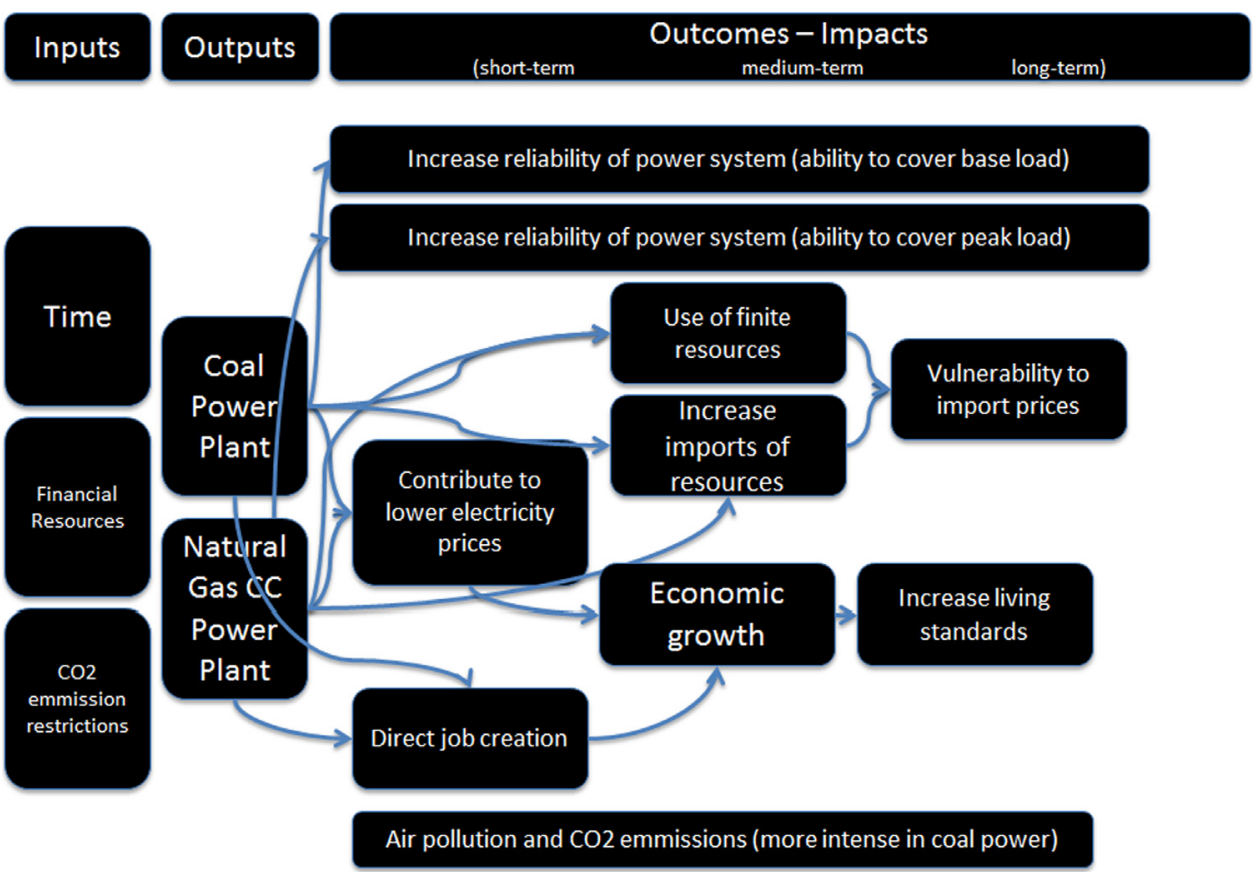

Fig. 5. The logic model for thermal power technologies. 


\section{Inputs}
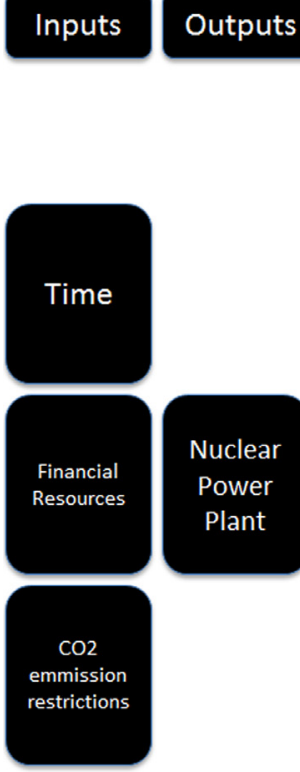

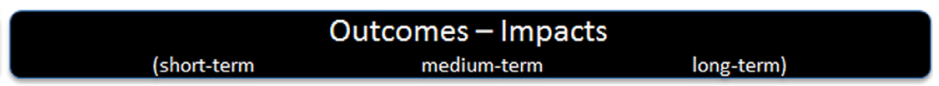

More resource

imports

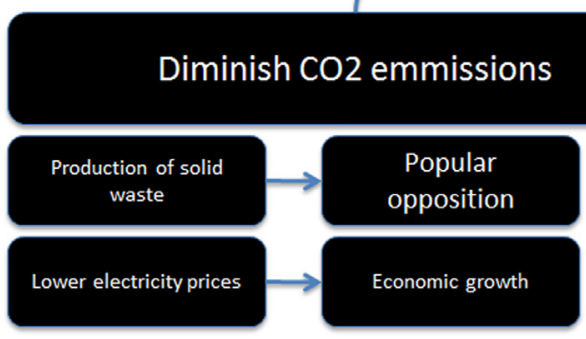

High investments in

transmission system

Market distortion

(market power)

Fig. 6. The logic model for nuclear power.

forms of generating (thermal power plants) electricity can help keeping the prices low on the short term. On the other hand there is the external energy dependency factor, which can be very much diminished in the long run, and would be difficult to achieve yet in a free-market environment, given the high costs of exploiting the renewables in the short-term. This duality is of extreme importance, and reflects what was said above: cost issues tend to prevail over social or environmental ones.

The remainder of the discussion will reflect topics that have arisen in the interviews, summarized in the diagrams of the previous section. The blocks shown in the logic models presented above appear in bold.

\subsection{Renewables}

The higher electricity prices topic is a disputed one, given some studies indicate that, among renewable sources being paid today with feed-in tariffs, some will be competitive around 2020, namely wind power [46]. On the other hand, it is also argued that until then, it leads to market distortions and it leaves less space for other energy sources to compete in the deregulated market. Transmission network expansion needed is also not consensual: during the interviews, some experts stated that lower losses in the power system are a consequence of the new paradigm of higher dispersion of generation groups, while others referred that those costs are passed, with lack of transparency, to all the consumers, not being accounted in renewable energy costs.

The block more reserve needed refers to the installed power as back-up, to compensate the renewables variable production. As a result, one interviewee mentioned the fact that the actual wind power capacity installed in Portugal already produces excessive energy in off-peak hours, resulting frequently in energy exported for free in those hours.

Everyone agreed that to prevent the need of more reserve units, some solutions exist: (a) to study the limits of the power system and to install variable electricity production sources according to those values; (b) to invest in demand-side management; (c) others, depending more on political factors, such as the integration in a wider European market by ending the bottleneck connection existent in the border of Spain and France.

The new infrastructures built around power plants were not seen as very important, given the fact that when they refer to roads, are normally away from large populated areas, therefore not resulting very useful, or at least a very important factor. This argument led us to contact local representatives of inhabitants that could be affected by roads constructed for wind farms, in order to listen to their informed perceptions: they said that local inhabitants felt they were in a better situation after the construction of these roads, although they also reported a minority of people who were annoyed. When the infrastructures refer to housing, major issues refer to the compensation after displacement, causing mostly displease to the affected population who also complain about landscape spoilage in those areas. Much positive and important at local level is, on the other hand, improvement of municipal income generated by these infrastructures: wind power is regarded as a successful case in rural areas with aging populations and facing youth emigration. The municipal budget generated by wind farms has been reported by local representatives to contribute for a better quality of life of local populations by means of newly built infrastructures, such as day care centers for elderly, among others.

General agreement was achieved on the connection between knowledge (R\&D), industrial clusters and external dependency. Portugal has presently two wind power clusters that provide valuable indirect employment and industrial activity, even possibly aiding the country to export more. According to the most of interviewees, it should be possible to lead the clusters to have a wider "national" value-chain, which would definitely induce a more durable economic development.

Studies on employment led by the use of renewables exist [49]. Although general agreement is that employment creation favours renewables, some interviewees emphasized that job quality and duration have to be addressed, and that renewables' projects are often creating low duration and low qualification jobs. The creation 
of jobs was seen by one interviewee as a critical point, since he argued that job creation in renewables is still subsidized and destroys jobs in more productive sectors of industry.

Although biomass based RES can contribute to a better forest management, biomass is not believed to occupy a central place in the near future renewable energy mix and will remain mainly used for cogeneration systems. General consensus exists however among interviewees concerning $\mathbf{C O}_{\mathbf{2}}$ emissions with all of them agreeing that those are definitely reduced by the use of renewable energy sources.

Although there is an agreement that the increment of renewables' use avoids exposition to fuel fossil prices and allows for less external dependency, in general economic terms the topics are less consensual among interviewees. This contribution of RES for electricity strategy can be discussed in the following terms: is it worth to invest now or later? If later, when? How long will natural gas and coal remain cheap? Anyway, the contribution of renewable energy source to the diversification of the electricity mix is seen as a very positive output for the Portuguese electricity system.

\subsection{Thermal power}

These technologies represent the status quo of power production. Although coal is generally seen as a source with less future than natural gas in the Portuguese power system, it can contribute to keep low electricity prices in the short run, at the cost of foreign dependency and vulnerability to finite resources price volatility.

Thermal power plants represent tested and reliable forms of producing power. Contrarily to renewable energy sources, they are not technologies of variable production, which means that their output can be more easily controlled. Coal is seen however as a natural polluter in the long run, whereas natural gas is seen as cleaner from this point of view. In fact, in the opinion of two interviewees, natural gas is a noble fossil fuel which should not be burnt to produce electricity.

The price of coal is more stable than the price of natural gas. The evolution of natural gas prices should depend very much on the regulatory framework, on how the Portuguese and Spanish market will evolve in the future and on decisive strategic investments in this area. Also, the ability of natural gas combined cycle power plants to contribute to lower electricity prices was stated to depend very much on the ability to integrate natural gas with wind power. If natural gas power plants tend to play a minor role in the electricity system, their production will end up covering only the few peak hours. This can lead to the misuse of these power plants, turning hard to justify such large investments. Therefore, no linear or clear relation exists between the power plant and low output price, but it rather depends on how the power plant is used.

As Portugal produces no natural gas, the use of this source increases importation of resources, and contributes for the resource depletion of the planet. Natural gas is seen as being able to create less direct jobs than coal power plants in the opinion of some of the interviewees: the use of coal involves more transportation and stocking management than natural gas.

\subsection{Nuclear power}

To what concerns nuclear power plants, it is agreed that only a large (in relation to the scale of Portugal) power plant would be feasible. This, depending on the chosen location, could implicate not only a redesign of the transmission grid, but could induce also market power problems that would have to be carefully studied by regulators. The vulnerability to resource prices is not seen as dangerous as in the cases of coal or natural gas, given the historical stability of prices and its low value, although some concerns about future resource depletion exist among the interviewees. The main problem of this option appears to be the high initial capital costs. Additionally, no know-how about nuclear power exists in Portugal, therefore knowledge and capital requirements have to account solely in the imports balance. Solid waste and popular opposition to power plants are very important matters yet, only expected to disappear if mankind manages to develop nuclear fusion technology and replace the traditional nuclear power plants. Diminishing the $\mathrm{CO}_{2}$ emissions appear to be a strong factor in favor of nuclear power. Among the interviewees, only one was welcoming a nuclear power plant.

\section{Conclusion and future work}

In this study, a wide array of impacts of three electricity generation options (renewable, thermal, nuclear) was assessed from literature review and interviews with experts in power systems, with the results of the research assuming the form of comprehensive impact chains or logic diagrams. Although in this case the logic models were specifically designed for the Portuguese case, much of its information can be generalized for other power systems. These diagrams are useful for structuring a decision-making problem of sustainability evaluation applied to power systems, giving guidance for informed top decision making, as proposed in Ribeiro et al. [51]. The same paper validated the usefulness of the impacts collected in the logical models, which can be weighted using tools that effectively take them into account in an explicit way, ensuring transparent decision-making [51].

The results of the present paper indicate that concerning electricity decisions an important contradiction still exists: the needed short term economic competitiveness and the long term goal of sustainability in power systems. This means that trade-offs must be considered for the definition of electricity strategies for the future. Although this is an assumption accepted in general, political and economic factors tend to influence significantly the decisions.

Given that the traditional sources are not limitless, RES will eventually have to play an important role in the future, when fossil fuels become more expensive. This will turn RES automatically attractive under an economic perspective. Before that time comes, RESs are still expensive, but meanwhile can foster knowledge, new industries and eventually economic growth, especially for countries such as Portugal, which relies mainly on foreign resources. In the short term it seems particularly important some gains brought to local population, mainly related to the increase of the community income or the building of new infrastructures. The expert interviews showed, however, some skepticism about the RES job creation potential and even about the RES ability to improve locals' quality of living. Further research turns out to be essential to proceed studying some cases in the Portuguese context, in order to recognize perceived negative and positive impacts.

As for thermal power plants, the importance of local impacts does not seem to be as significant. The general view of experts clearly favours that national level impacts are the most important ones, turning the local impact assessment studies a less important requirement for the verification of the logic models. In fact, most of the impacts related to $\mathrm{CO}_{2}$ emissions, cost or volatility of fossil fuel prices may be evaluated resourcing to mathematical models such as Pereira et al. [52].

This research aimed to demonstrate the use of qualitative tools such as the logic models to feed impact assessment studies for the electricity sector, including the evaluation of economic, environmental and social impacts. The work was supported on literature 
review and feedback from experts and/or stakeholder and allowed to recognize expected short-term and long-term effects of different technologies or groups of technologies. However, the results also revealed the need to proceed with an in-deeper analysis of these impacts. Future work envisages two main routes: (1) the modeling and use of multicriteria tools aiming to weight the importance of the components of the logic models, to evaluate the sustainability of future scenarios of electricity production and (2) the assessment of local and regional social impacts of RES projects, supported on qualitative methodologies based mainly on interviews with different local stakeholders.

\section{Acknowledgment}

Authors wish to thank the participants in the interviewing process. This work was financed by the QREN - Operational Programme for Competitiveness Factors, the European Union European Regional Development Fund and National Funds Portuguese Foundation for Science and Technology, under Project FCOMP-01-0124-FEDER-011377 and Project Pest-OE/EME/UI0252/ 2011.

\section{References}

[1] European Commission, renewed EU sustainable development strategy. Brussels; 2005.

[2] European Commission, package of implementation measures for the EU's objectives on climate change and renewable energy for 2020. Brussels; 2008.

[3] Ferreira P, Araújo M, O'Kelly M. The integration of social concerns into electricity power planning: a combined Delphi and AHP approach. In: Rebennack S, Pardalos PM, Pereira MVF, Iliadis NA, editors. Handbook of power systems; 2010. p. 323-64.

[4] Ribeiro F, Ferreira P, Araújo M. The inclusion of social aspects in power planning. Renewable and Sustainable Energy Reviews 2011:15(9):4361-9.

[5] República Portuguesa, Plano nacional de acção para as energias renováveis aoabrigo da directiva 2009/28/CE [in Portuguese]; 2009. Available from: 〈http://www.apisolar.pt/images/stories/Politica_Energetica/PNAER.pdf $\rangle$ (May 2012).

[6] UNDP, climate change: fast facts, United Nations Development Programme; 2011. Available from: 〈http://www.undp.org/content/dam/undp/library/corpo rate/fast-facts/english/FF-Climate-Change.pdf), (May 2012).

[7] European Commission, ExternE. Externalities of energy, vol. 7, Methodology 1998 update.

[8] Jegarl S, Baek J-I, Jang D-S, Ryu C-K. Impact assessment of $\mathrm{CO}_{2}$ mitigation options in Korea using energy system analysis model, Energy Procedia 2009;1 (1) 3747-54. In: Proceedings of the 9th international conference on greenhouse gas control technologies (GHGT). Washington DC, USA; 16-20 November 2008.

[9] Tolis AI, Rentizelas AA. An impact assessment of electricity and emission allowances pricing in optimised expansion planning of power sector portfolios. Applied Energy 2011;88(11):3791-806.

[10] Hugé J, Waas T, Eggermont G, Verbruggen A. Impact assessment for a sustainable energy future: reflections and practical experiences. Energy Policy 2011;39(10):6243-53.

[11] del Río P, Burguillo M. An empirical analysis of the impact of renewable energy deployment on local sustainability. Renewable and Sustainable Energy Reviews 2008;13(6-7):1314-25.

[12] Sastresa EL, Usón AA, Bribián IZ, Scarpellini S. Local impact of renewables on employment: assessment methodology and case study. Renewable and Sustainable Energy Reviews 2010;14(2):679-90.

[13] Onat N, Bayar H. The sustainability indicators of power production systems. Renewable and Sustainable Energy Reviews 2010;14(9):3108-15.

[14] Shropshire D. Economic viability of small to medium-sized reactors deployed in future european energy markets. Progress in Nuclear Energy 2011;53 (4):299-307

[15] Krewitt W. External costs of energy - do the answers match the questions?: Looking back at 10 years of ExternE Energy Policy 2002;30(10):839-48.

[16] World Commission on Environment and Development, our common future, Oxford University Press; 1987, (full text available at 〈http://en.wikisource.org/ wiki/Brundtland_Report)).

[17] Blanco MI, Rodrigues G. Direct employment in the wind energy sector: an EU study. Energy Policy 2009;37(8):2847-57.

[18] Ciorba U, Pauli F, Menna P. Technical and economical analysis of an induced demand in the photovoltaic sector. Energy Policy 2004;32(8):949-60.

[19] Capros P, Karadeloglou P, Mentzas G. Employment impacts of energy: a survey and framework for analysis. Socio-Economic Planning Sciences 1992;26 (4):257-74.
[20] European Commission, 〈http://ec.europa.eu/social/main.jsp?catld=760\&langId=en $\rangle$ (May 2012).

[21] Leeuw F, Vaessen J. Impact evaluations and development: NONIE guidance on impact evaluation. Washington DC; 2009.

[22] Ruddy T, Hilty LM. Impact assessment and policy learning in the European Commission. Environmental Impact Assessment Review 2008;28(23):90-105.

[23] Bäcklund A. Impact assessment in the European Commission: a system with multiple objectives. Environmental Science and Policy 2009;12(8): 1077-87.

[24] ECORSYS Nederland BV. Assessing the employment and social impacts of selected strategic commission policies, Final Report. DG employment, social affairs and equal opportunities of the European Commission. Rotterdam; 2009.

[25] Renger R, Titcomb A. A three-step approach to teach logic models. American Journal of Evaluation 2002;23(4):493-503.

[26] Kim M, Sung Y. A performance and monitoring evaluation system \& its applications for National R\&D Programs: a case of industrial application technology in Korea. In: Proceedings of PICMET. Cape Town; 27-31 July 2008, p. 386-94

[27] Oros C, Doan H, Adoum D, MacDonald R. Portfolio review expert panel process: a tool for accountability and strategic planning to meet research goals. Research Evaluation 2007;16(3):157-67.

[28] Helitzer D, Hollis C, Hernandez BU, Sanders M, Roybal S, van Deusen I. Evaluation for community-based programs: the integration of logic models and factor analysis. Evaluation and Program Planning 2010;33:223-33.

[29] Medeiros L, Buktus S. A logic model framework for community nutrition education. Journal of Nutrition Education and Behavior 2005;37(4):197-202.

[30] Scarinci Isabel C, Johnson Rhoda E, Hardy Claudia, Marron John, Partridge Edward E. Planning and implementation of a participatory evaluation strategy: a viable approach in the evaluation of community-based participatory programs addressing cancer disparities. Evaluation and Program Planning 2009;32(3):221-8

[31] Hill JR, Thies J. Program theory and logic model to address the co-occurrence of domestic violence and child maltreatment. Evaluation and Program Planning 2010;33(4):356-64.

[32] Randolph J, Eronen J. Developing the learning door: a case study in youth participatory program planning. Evaluation and Program Planning 2007;30 (1):55-65.

[33] Sanou A, Kouyaté B, Bibeau G, Nguyen V-K. Evaluability assessment of an immunization improvement strategy in rural Burkina Faso: intervention theory versus reality, information need and evaluations. Evaluation and Program Planning 2011;34(3):303-15.

[34] Ziviani J, Darlington Y, Feeney R, Head B. From policy to practice: a program logic approach to describing the implementation of early intervention services for children with physical disability. Evaluation and Program Planning 2011;34 (1):60-8.

[35] O'Faircheallaigh C. Public participation and environmental impact assessment: purposes, implications, and lessons for public policy making. Environmental Impact Assessment Review 2010;30(1):19-27.

[36] Bond A, Palerm J, Haigh P. Public participation in EIA of nuclear power plant decommissioning projects: a case study analysis. Environmental Impact Assessment Review 2004;24(6):617-41.

[37] Portman M. Involving the public in the impact assessment of offshore renewable energy facilities. Marine Policy 2009;33(2):332-8.

[38] Gamboa G, Munda G. The problem of windfarm location: a social multicriteria evaluation framework. Energy Policy 2007;35(3):1564-83.

[39] Kowalski K, Stagl S, Madlener R, Omann I. Sustainable energy futures: methodological challenges in combining scenarios and participatory multicriteria analysis. European Journal of Operational Research 2009;197 (3):1063-74

[40] Carrera DG, Mack A. Sustainability assessment of energy technologies via social indicators: results of a survey among European energy experts. Energy Policy 2010;38(2):1030-9.

[41] Karger CR, Hennings W. Sustainability evaluation of decentralized electricity generation. Renewable and Sustainable Energy Reviews 2009;13(3):583-93.

[42] Kaya T, Kahraman C. Multicriteria decision making in energy planning using a modified fuzzy TOPSIS methodology. Expert Systems with Applications 2011;38(6):6577-85.

[43] Adams M, Wheeler D, Woolston G. A participatory approach to sustainable energy strategy development in a carbon-intensive jurisdiction: the case of Nova Scotia. Energy Policy 2011;39(5):2550-9.

[44] McLaughin J, Jordan G. Logic models: a tool for telling your program's performance story. Evaluation and Program Planning 1999;22:65-72.

[45] APREN \& Deloitte, Impacto Macroeconómico do Sector das Energias Renováveis; 2009 [in Portuguese]. Available from: 〈http://www.apren.pt/fotos/noti cias/apren_impacto_energias_renovaveis_1266829068.pdf).

[46] APREN, assessment of costs and benefits of electricity production from renewable energy sources; 2011. Available from: 〈http://www.apren.pt/fotos/ editor2/destaques/apren_rb_costs_benefits_of_renewables_executivesum mary.pdf\%20>.

[47] INAG, Plano nacional de barragens com elevado potencial hidroeléctrico; 2007 [in Portuguese].

[48] REN, Redes Energéticas Nacionais, A energia eólica em Portugal; 2011 [in Portuguese]. Available from: 〈http://www.centrodeinformacao.ren.pt/PT/pub licacoes/EnergiaEolica/A\%20Energia\%20E\%C3\%B3lica\%20em\%20Portugal\%20-\% 202011.pdf?. 
[49] REN, Redes Energéticas Nacionais, Informação mensal sistema electroprodutor [in Portuguese]. Available from: 〈http://www.centrodeinformacao.ren.pt/EN/ InformacaoExploracao/Pages/EstatisticaMensal.aspx> (May, 2013).

[50] ERSE, Informação sobre Produção em Regime Especial - dados actualizados a Dezembro de 2012, Entidade Regulador dos Serviços Energéticos [in Portuguese]. Available from: 〈http://www.erse.pt/pt/electricidade/factosenumeros/ Documents/SIPREinfoDez12.pdf).
[51] Ribeiro Fernando, Ferreira Paula, Araújo Madalena. Evaluating future scenarios for the power generation sector using a multi-criteria decision analysis (MCDA) tool: the Portuguese case. Energy 2013;52:126-36.

[52] Pereira S, Ferreira P, Vaz AI. Strategic electricity planning decisions. In: Proceedings of the Dubrovnik conference on sustainable development of energy, water and environment systems. Dubrovnik, Croatia; 25-29 September 2011. p. 590. 